\title{
Low-Concentration Methylene Blue Maintains Energy Production and Strongly Improves Survival of Leigh Syndrome French Canadian Skin Fibroblasts
}

\author{
Jean Legault ${ }^{\mathrm{a}}$, Pierre-Luc Larouche ${ }^{\mathrm{a}}$, Isabelle Côté ${ }^{\mathrm{a}}$, Line Bouchard ${ }^{\mathrm{a}}$, André Pichette ${ }^{\mathrm{a}}$, Brian H. Robinson ${ }^{\mathrm{b}}$ and Charles \\ Morin $^{\mathrm{a}, \mathrm{c}}$ \\ ${ }^{a}$ Department of fundamental sciences, Université du Québec à Chicoutimi, Chicoutimi, Québec, Canada. \\ ${ }^{b}$ Department of Paediatrics, The Hospital for Sick Children, Research Institute, Toronto, Canada. \\ ${ }^{\mathrm{c}}$ Department of Pediatrics and Clinical Research Unit, Complexe hospitalier de la Sagamie, Chicoutimi, QC, Canada.
}

Received, August 8, 2011; Accepted, November 23, 2011; Published, November 26, 2011.

\begin{abstract}
Leigh syndrome French Canadian (LSFC) is a recessive disease caused by mutations in the LRPPRC gene (leucine-rich pentatricopeptide repeat containing protein). These mutations induce a cytochrome c oxidase (COX) deficiency resulting in episodes of acute acidotic crisis that will often lead to death. There is no effective treatment. Methylene blue (MB) is a redox dye that increases COX content and activity in vitro and in vivo suggesting that MB could prevent and treat LSFC. In this study, the protective effect of low-concentration MB was tested on two LSFC cell lines, including LSFC-F1, homozygous for the mutation A354V, and LSFC-F2 a compound heterozygous for the mutations A354V and C1277STOP. MB effect on metabolic activity was assessed on both LSFC cells in stable and acidotic conditions. For LSFC-F1, results showed that metabolic activity drastically decline after 96 hours in both conditions but not LSFC-F2 and normal cells. MB completely prevents the decrease of metabolic activity in LSFC-F1. Intracellular ATP content was also measured in both culture media. After 96 hours in acidotic medium, ATP content was almost completely depleted for both LSFC cells. Interestingly, MB completely restores ATP content in LSFC-F1 and LSFC-F2 cells. Finally, MB strongly improves the survival of both LSFC cells.
\end{abstract}

This article is open to POST-PUBLICATION REVIEW. Registered readers (see "For Readers") may comment by clicking on ABSTRACT on the issue's contents page.

\section{INTRODUCTION}

The French Canadian variant of Leigh syndrome (Leigh Syndrome French Canadian, or LSFC), also commonly called lactic acidosis, is a recessive disease caused by mutations in the LRPPRC gene (leucine-rich pentatricopeptide repeat containing protein) on chromosome $2 \mathrm{p} 16-21$. One mutation $\left(\mathrm{Ala}^{354} \rightarrow \mathrm{Val}\right)\left[\mathrm{C}^{1119} \rightarrow \mathrm{T}\right]$ was found responsible for $95 \%$ of the cases of LSFC in the Saguenay-LacSt-Jean region $(1,2)$. One individual had an $8 \mathrm{bp}$ deletion in exon 35 creating a premature stop codon thus producing one compound heterozygote. Children who suffer from this illness are hypotonic and have psychomotor delay (3). Classical Leigh syndrome presents with typical characteristics such as ataxia, dystonia, optic nerve atrophy, ophthalmoplegia, ptosis, nystagmus, trembling and respiratory system alterations. However, the LSFC symptoms are less severe than those observed in the "classical" Leigh syndrome (3). In LSFC, energy production is altered since the cells of children suffering from this disease produce less energy (ATP) than normal cells (4). This reduced energy production is caused by a deficit in cytochrome c oxidase (COX), an enzyme involved in the electron transfer chain of mitochondria (4). Recently, Sasarman et al., showed that the level of mutated LRPPRC is reduced in LSFC cells resulting in decreased steady-state levels of most mitochondrial mRNAs and proteins which lead to a COX assembly defect (5). In a normal, unstressful situation, afflicted children can overcome this deficiency. However, a sustained physical effort, an emotional shock or an infection can all prove fatal.

Corresponding Author: J. Legault, $\mathrm{PhD}$, Department of fundamental sciences, Université du Québec à Chicoutimi, 555, boulevard de l'Université, Chicoutimi, Québec, Canada, Email: Jean_Legault@uqac.ca 
These stresses may result in an acute acidotic crisis with excessive accumulation of lactic acid that leads to coma and death (3). Many tissues isolated from LSFC children express low COX activity, noticeably in the brain and liver (10 to $20 \%$ of the normal activity) (4). Some tissues, such as skin (fibroblasts) and skeletal muscle, maintain $50 \%$ of their normal COX activity, while tissues such as heart and kidney show almost normal levels of COX activity (4). To date, there is no effective treatment available.

The redox agent methylthioninium chloride or methylene blue (MB) is an organic dye from the diaminophenothiazine family with cationic and lipophilic properties that acts as an electron transfer mediator in the mitochondria (6-9). Atamna et al. (9) demonstrated that nanomolar range of $\mathrm{MB}$ delays cellular senescence of normal human fibroblasts and increases oxygen consumption, heme synthesis and resistance to oxidative damage. Interestingly, $\mathrm{MB}$ could also increase the cellular contents of cytochrome c oxidase. The promising properties of $\mathrm{MB}$ prompted us to evaluate its potential on cells affected by LSFC.

The objective of this study was to evaluate the protective effect of MB on two skin fibroblast cell lines isolated from LSFC patients. The effect of MB on metabolic activity, ATP content and cell survival was assessed with regard to two culture conditions, i.e. a stable and an acidotic media. The results showed that MB maintains metabolic activity, ATP content and improves the survival of two LSFC cells tested.

\section{Materials and Methods}

\section{Primary explant and cell culture}

The normal human skin fibroblast cell line, WS1 (ATCC \#CRL-1502) was obtained from the American Type Culture Collection (ATCC, Manassas, VA, USA). The LSFC cell lines were obtained - after informed consent - from skin biopsies of two patients, using primary explants (10). A pure skin fibroblast cell line was obtained from each patient. The LSFC cell lines were named LSFC-F1 for the homozygous (A354V) and LSFC$\mathrm{F} 2$ for the compound heterozygous (A354V and C1277STOP). The cell lines were grown in Dulbecco's Modified Eagle's Medium (Mediatech Cellgro ${ }^{\circledR}$, Herndon, USA). The culture medium was supplemented with $10 \%$ fetal calf serum
(Hyclone, Logan, USA); a solution of vitamins containing : D-calcium pantothenate $(1 \mathrm{mg} / \mathrm{L})$, choline chloride $(1 \mathrm{mg} / \mathrm{L})$, folic acid $(1 \mathrm{mg} / \mathrm{L})$, inositol $(2 \mathrm{mg} / \mathrm{L})$, Nicotinamide $(1 \mathrm{mg} / \mathrm{L})$, Pyridoxine (1 $\mathrm{mg} / \mathrm{L})$, Riboflavin $(0.1 \mathrm{mg} / \mathrm{L})$, Thiamine $(1 \mathrm{mg} / \mathrm{L})$; sodium pyruvate $(10 \mathrm{mM})$; non-essential amino acids solution containing : Lalanine $(8.9 \mathrm{mg} / \mathrm{L})$, L-asparagine $(15 \mathrm{mg} / \mathrm{L})$, Laspartic acid (13.3 mg/L), L-glutamic acid (14.7 $\mathrm{mg} / \mathrm{L})$, glycine $(7.5 \mathrm{mg} / \mathrm{L})$, L-proline $(11.5 \mathrm{mg} / \mathrm{L})$, L-serine $(10.5 \mathrm{mg} / \mathrm{L})$; penicillin $(100 \mathrm{IU})$ and streptomycin $(100 \mu \mathrm{g} / \mathrm{ml})$ (Mediatech Cellgro $\left.{ }^{\circledR}\right)$. Cells were cultured in a humidified atmosphere at $37^{\circ} \mathrm{C}$ in $5 \% \mathrm{CO}_{2}$. This study was approved by the Comité d'éthique à la recherche de l'Université du Québec à Chicoutimi and the Comité d'éthique à la recherche du Complexe hospitalier de la Sagamie.

\section{Assessment of COX activity}

Isolated mitochondria were prepared as described by Pitkänen et al. (11). Protein concentration of the mitochondrial fraction was determined using Bradford's method with BSA as a standard (12). The cytochrome $\mathrm{c}$ oxidase (COX) and citrate synthase (CS) activities were measured as described by Kramer et al. (13) at the same protein concentration. The COX activity was expressed as $\mathrm{COX} / \mathrm{CS}$ ratio.

\section{Methylene blue treatment}

Methylene blue, MB (chemical grade; purity $\geq$ 95\%), was obtained from Sigma-Aldrich (St-Louis, MO, USA). The cells were treated with or without $125 \mathrm{nM} \mathrm{MB}$ during 24 or 96 hours in a stable medium containing Earl's Salt medium base, $4 \mathrm{mM}$ glucose, $4 \mathrm{mM}$ lactate, $18 \mathrm{mM}$ sodium bicarbonate at a $\mathrm{pH}$ adjusted to 7.3 or in an acidotic medium containing Earl's Salt medium base, $30 \mathrm{mM}$ glucose, $10 \mathrm{mM}$ lactate, $7 \mathrm{mM}$ sodium bicarbonate at a $\mathrm{pH}$ adjusted to 7.0 .

\section{Metabolic activity using resazurin}

Exponentially growing cells were plated at a density of $1 \times 10^{4}$ cells per well in 96-well microplates (Costar, Corning Inc.) in $100 \mu \mathrm{l}$ of culture medium and were allowed to adhere for 24 hours before treatment. The cells were treated with or without $125 \mathrm{nM} \mathrm{MB}$ in a stable medium or an acidotic medium. After $24 \mathrm{~h}$ or $96 \mathrm{~h}, 10 \mu \mathrm{l}$ of a solution of resazurin $4 \%$ was added to each well and the plates were incubated 60 minutes at $37^{\circ} \mathrm{C}$ 
(14). Fluorescence was measured on an automated Fluoroskan Ascent Fl plate reader (Labsystems) using an excitation wavelength of $530 \mathrm{~nm}$ and an emission wavelength of $590 \mathrm{~nm}$. The metabolic activity was reported on the relative quantity of DNA found in each well using Hoechst assay (15). Briefly, the medium was removed from the wells. The cells were washed with PBS buffer, $\mathrm{pH} 7.4$ (Sigma-Aldrich, St-Louis, MO, USA) and the plates were frozen at $-80^{\circ} \mathrm{C}$ for 24 hours. The plates were then thawed to room temperature and shaken for three hours with $100 \mu \mathrm{L}$ of SDS $0.01 \%$ per well. The plates were again frozen for 24 hours at $-80^{\circ} \mathrm{C}$ and thawed to room temperature. Then, we added to each well $100 \mu \mathrm{L}$ of solution containing $60 \mathrm{ng} / \mathrm{mL}$ Hoechst 33342 in TNE buffer (10 mM Tris-HCl, 1 $\mathrm{mM}$ EDTA, $4 \mathrm{M} \mathrm{NaCl}$ ) adjusted to $\mathrm{pH}$ 7.4. The plates were shaken for 2 hours at room temperature in the dark. Fluorescence was then measured (ex.: $460 \mathrm{~nm}$; em.: $530 \mathrm{~nm}$ ). Regardless of the conditions tested $(n>30)$, the mean of relative Hoechst fluorescence for WS1, LSFC-F1 and LSFC-F2 was $8 \pm 1,2.0 \pm 0.4$ and $2.6 \pm 0.5$, respectively.

\section{Assessment of ATP content}

Exponentially growing cells were plated at a density of $10^{4}$ cells per well in 96-well microplates (Costar, Corning Inc.) in $100 \mu 1$ of culture medium and were allowed to adhere for 24 hours before treatment. Then, the cells were treated with or without $125 \mathrm{nM} \mathrm{MB}$ in a stable medium or an acidotic medium for 24 or 96 hours. The cells were washed with PBS and $100 \mu \mathrm{l}$ of boiling distilled demineralized water was added to the cells (16). Five microliters from each sample was added to an opaque microplate. Using an automated system, 45 $\mu \mathrm{L}$ of a reaction solution (D-luciferin $0.5 \mathrm{mM}$; DTT $1 \mathrm{mM}$; firefly luciferase $1.25 \mu \mathrm{g} / \mathrm{mL}$ ) was injected and light emission was measured immediately over 10 seconds. ATP content of samples was determined using standard curves with known concentrations of ATP and expressed as ATP/Hoechst ratio.

\section{Survival assay using calcein-AM}

Exponentially growing cells were plated at a density of $10^{4}$ cells per well in 96-well microplates (Costar, Corning Inc.) in $100 \mu \mathrm{l}$ of culture medium and were allowed to adhere for 24 hours before treatment. Then, the cells were treated 96 hours with or without $125 \mathrm{nM} \mathrm{MB}$ in a stable medium or an acidotic medium. The viability of cells was assessed by the presence of intracellular esterase activity using calcein-AM (Invitrogen, Burlington) (17). The probe was diluted at a final concentration of $4 \mu \mathrm{M}$ and added directly to the cells. The plates were incubated at $37^{\circ} \mathrm{C}$ with $5 \% \mathrm{CO}_{2}$ for 2 hours and fluorescence (ex.: $485 \mathrm{~nm}$; em.: $530 \mathrm{~nm}$ ) was read using a Fluoroskan Ascent FL plate reader (Labsystems).

\section{STATISTICAL ANALYSIS}

In all studies the values were expressed as means \pm standard deviation of six determinations. The distribution of each group was found to be normal by using the Kolmogorov-Smirnov test ( $p>0.200)$. The results were analyzed by one-way ANOVA followed by a post-hoc Bonferroni test. P values of 0.05 or less were considered statistically significant.

\section{RESULTS}

\section{Cytochrome oxidase activity of Leigh Syndrome French Canadian skin fibroblasts.}

COX activity was evaluated on isolated mitochondria. Results presented in Figure 1 are expressed as the ratio of COX activity on citrate synthase (CS) activity made on the same quantity of proteins. The $\mathrm{COX} / \mathrm{CS}$ ratio for normal skin fibroblasts (WS1) and Leigh Syndrome French Canadian skin fibroblasts, LSFC-F1 and LSFC-F2, was $1.0 \pm 0.2,0.47 \pm 0.05$ and $0.5 \pm 0.1$ respectively. The COX activity for both LSFC cells was significantly lower, i.e. about $52 \%$ in comparison with normal fibroblast WS1. No significant difference was found between LSFC-F1 and LSFC-F2. These results agree with those reported in the literature (4).

Effect of methylene blue on metabolic activity and ATP content of Leigh Syndrome French Canadian skin fibroblasts.

The effect of MB on the metabolic activity of WS1 and LSFC cells was evaluated using resazurin in two culture media with regard to physiological blood concentration of glucose, lactate, bicarbonate and $\mathrm{pH}$ measured in LSFC patients before (stable medium) and during the acidotic crisis (acidotic medium). Optimal concentration of MB was firstly 
determined in acidotic medium. LSFC cells were incubated in the presence or absence of growing concentrations of MB ranging from 0,016 to $10 \mu \mathrm{M}$ for 24 and 96 hours. After 24 hours, the results presented in Figure 2 show that MB does not affect significantly the metabolic activity of LSFC cells. After 96 hours in acidotic medium, a decrease of $77 \%$ of the metabolic activity was observed in comparison with 24 hours. MB significantly increases metabolic activity between 0.031 and 1 $\mu \mathrm{M}$ with a maximum at $0.125 \mu \mathrm{M}$. However, $\mathrm{MB}$ induced significant cytotoxicity at concentrations of 5 and $10 \mu \mathrm{M}$. Consequently, the optimal concentration of $\mathrm{MB}$ used in this study was
$0.125 \mu \mathrm{M}(125 \mathrm{nM})$. The possibility that MB directly interacts with resazurin was investigated. The effect of $\mathrm{pH}$ was also tested. Resazurin was incubated, without cells, for 1 hour in the absence or in the presence of $\mathrm{MB} 125 \mathrm{nM}$ at $\mathrm{pH}$ ranging from 5.5 to 7 . The basic fluorescence at time 0 was compared with fluorescence after 1 hour of incubation. The results indicate that MB does not react directly with resazurin (data not shown). Moreover, the results show also that $\mathrm{pH}$ does not promote direct reaction of $\mathrm{MB}$ with resazurin (data not shown). Consequently, the effects of MB are induced by biological effects.

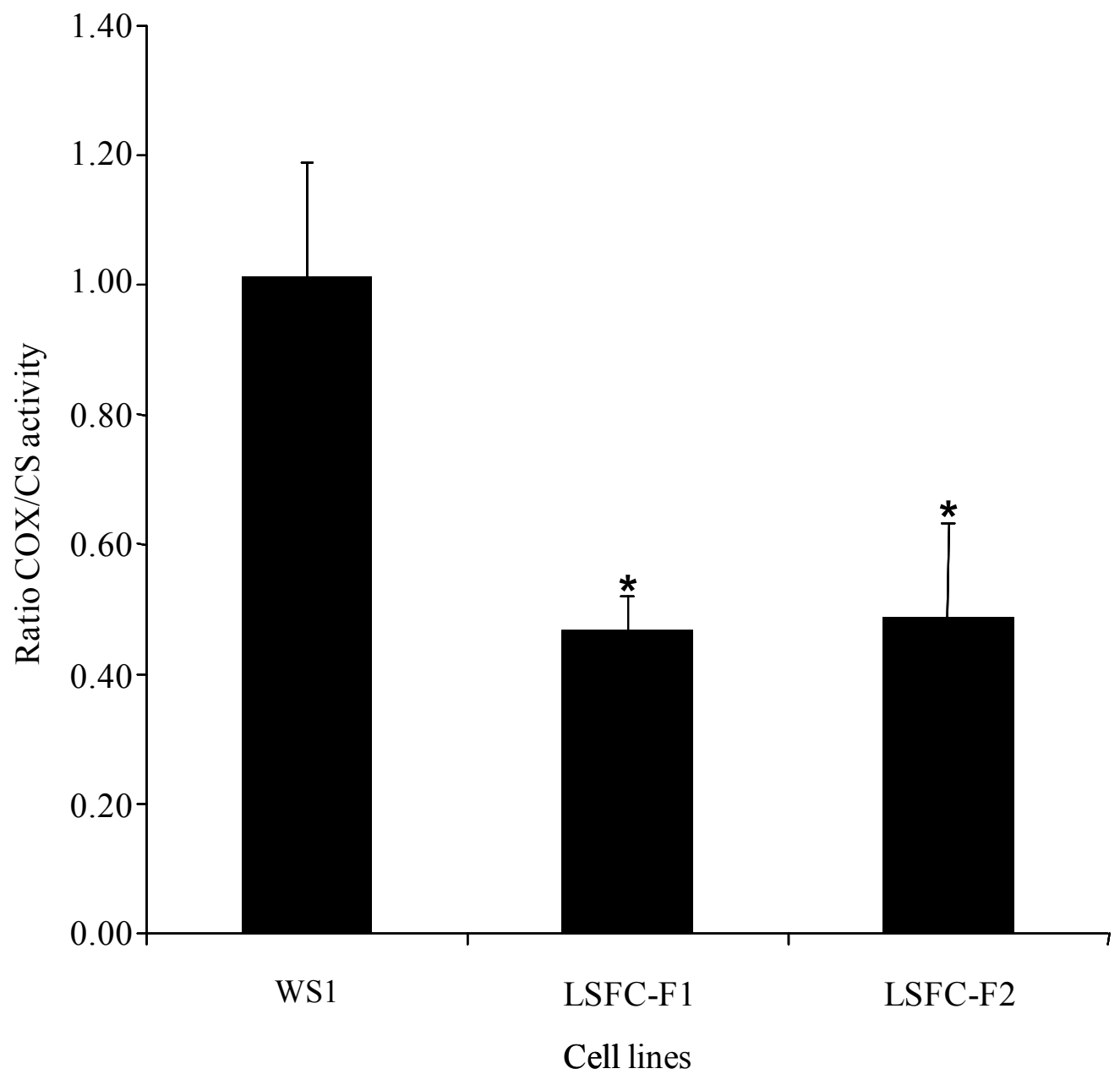

Fig. 1 Cytochrome c oxidase activity of normal (WS1) and Leigh Syndrome French Canadian (LSFC) skin fibroblasts. Data represent the means \pm standard deviation of six determinations. *Significantly different from normal skin fibroblasts WS1; $\mathrm{P} \leq 0.05$, one-way ANOVA analysis and post-hoc Bonferroni test. 


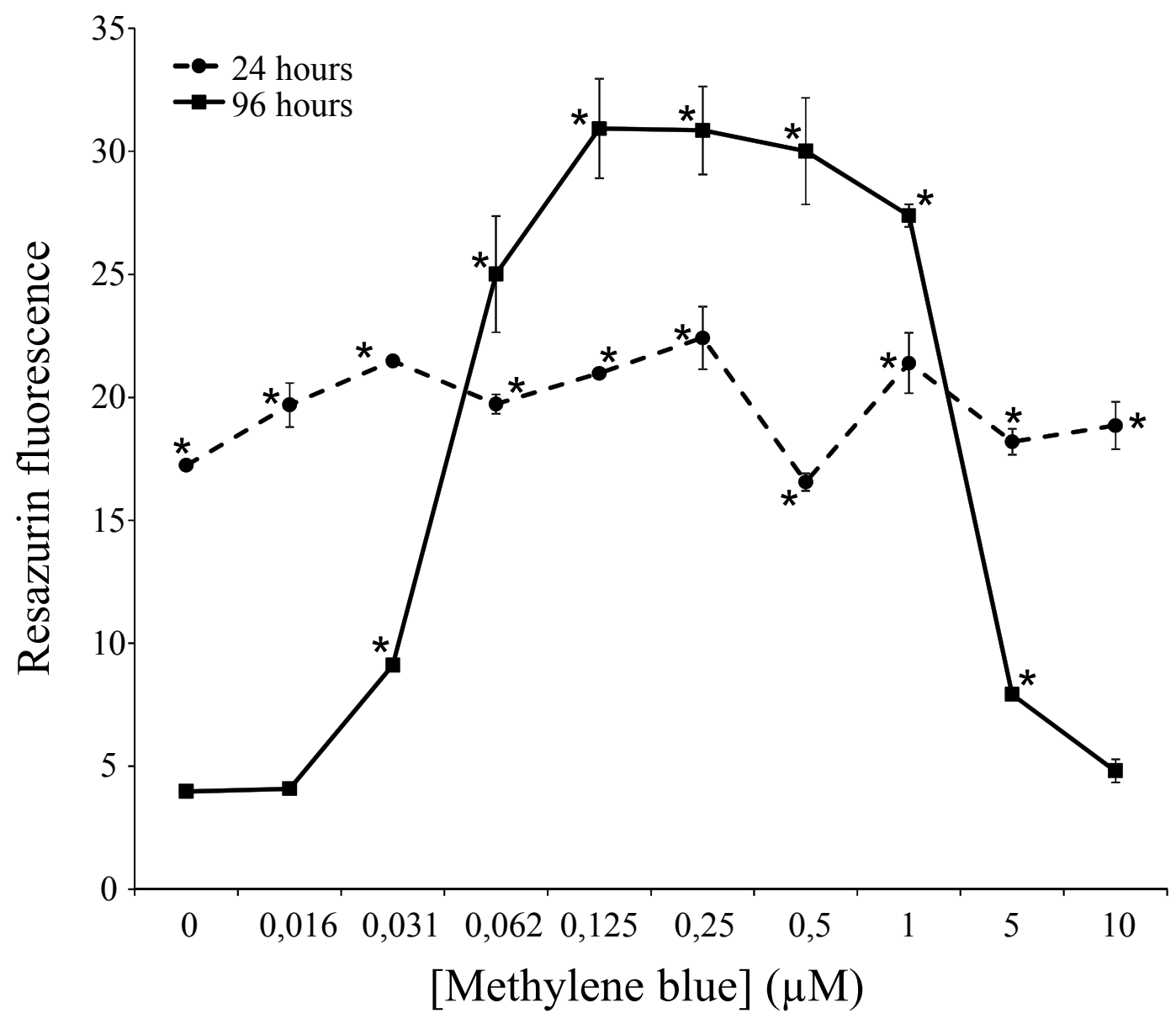

Fig. 2 Concentration-response curve of LSFC cells treated with or without methylene blue $(0.016$ to $10 \mu \mathrm{M})$ in acidotic medium for 24 and 96 hours. Data represent the means \pm standard deviation of at least six determinations. *Significantly different from MB-untreated cells at $96 \mathrm{~h} . \mathrm{P} \leq 0.05$, one-way ANOVA analysis and post-hoc Bonferroni test.

To compare the effect of MB on the metabolic activity of normal and LSFC skin fibroblasts, the cells were treated with or without $125 \mathrm{nM} \mathrm{MB}$ for 24 and 96 hours in a stable medium or an acidotic medium. The metabolic activity was reported on the relative quantity of DNA found in each well. Results presented in Figure 3 show that after 96 hours the metabolic activity of WS1 significantly increased by approximately $43 \%$ in a stable medium and by approximately $76 \%$ in the acidotic medium in comparison to 24 hours. However, no change was observed for LSFC-F2. In contrast, a drastic decrease of metabolic activity was observed for LSFC-F1 after 96 hours in both media. The decline of the metabolic activity is completely prevented by MB in the stable medium (Figure 3A) and the acidotic medium (Figure 3B). Moreover, MB significantly increases the metabolic activity of LSFC-F2 after 96 hours in the acidotic medium in comparison with untreated cells. However, MB has no significant effect on metabolic activity of LSFCF2 after 24 hours and on WS1 after 24 and 96 hours. On the other hand, it is interesting to note that, after 24 hours in the stable medium (Figure $3 \mathrm{~A})$ the metabolic activity of LSFC-F1 is significantly higher, about $130 \%$ in comparison with normal cells. Moreover, after $24 \mathrm{~h}$ in the acidotic medium (Figure 3B), the metabolic activity of both LSFC cell lines is higher in comparison with WS1. Altogether, these results suggest that MB could prevent the decline of metabolic activity and protect energy homeostasis in LSFC cells. 
Therefore, the effect of MB on ATP content was assessed on both LSFC cells and compared with WS1. ATP content was reported on the relative quantity of DNA found in each well. The results presented in Figure 4 show that, at 24 hours, the ATP content is about $40 \%$ to $60 \%$ lower in both LSFC cell lines in comparison with WS1 in the stable (Figure 4A) and acidotic media (Figure 4B). After 96 hours, the ATP content of LSFC-F1 was significantly decreased by approximately $73 \%$ in the stable medium and by approximately $97 \%$ in the acidotic medium compared with untreated cells at 24 hours. The treatment with MB completely prevents the decline of ATP in both media. As observed in WS1, the ATP content in LSFC-F2 did not decrease in the stable medium after 96 hours (Figure 4A). In contrast, a significant decrease was observed after 96 hours for WS1 and LSFC-F2 in the acidotic medium (Figure 4B). The decline of ATP is more marked for LSFC-F2 with a decrease of $91 \%$ compared with a decrease of $53 \%$ for the WS1. Interestingly, MB completely restores the ATP content in LSFC-F2 but not in WS1. Altogether, these results show that $\mathrm{MB}$ can maintain ATP content in both LSFC cell lines and suggest that MB could allow the improvement of cell survival.

\section{Effect of methylene blue on survival of Leigh Syndrome French Canadian skin fibroblasts.}

To assess the effect of MB on cell survival, the LSFC-F1, LSFC-F2 and WS1 cells were treated with or without $125 \mathrm{nM} \mathrm{MB}$ for 24 and 96 hours. The percentage of survival of cells at 96 hours was calculated from calcein fluorescence at 24 hours which is considered as $100 \%$ of survival. Results presented in Figure 5 show that the percentage of survival of WS1, ranging from $54 \%$ to $69 \%$, was not significantly different between the two culture media. Moreover, MB did not improve cell survival. Interestingly, the survival of LSFC-F2 is significantly higher than normal cells in the stable medium with $82 \%$ but not in the acidotic medium with $40 \%$ of survival. The MB treatment of LSFCF2 increases cell survival in the stable and acidotic medium to approximately $27 \%$ and $54 \%$ respectively compared to untreated cells. Finally, LSFC-F1 cells did not survive in the two culture media after 96 hours. However, MB strongly improves the survival of LSFC-F1 in both media with $82 \%$ and $99 \%$ of survival, respectively.
Altogether, these results indicate that MB strongly improves the survival of both LSFC cells.

\section{Discussion}

LSFC disease is characterized by COX deficiency which can result in acidotic crises and lead to coma and death $(3,4)$. Some studies show that $\mathrm{MB}$ increases COX content and activity suggesting that MB could prevent acidotic crises in LSFC disease $(9,18)$. MB effect was evaluated on a spatial memory retention deficit in rats induced by a COX inhibitor, sodium azide. MB was shown to increase mitochondrial respiration at low doses ranging from 0.1 to $2 \mu \mathrm{M}$, transferring electrons from complex IV to oxygen $(6,9,19,20)$. Interestingly, administration of a low dose of methylene blue (1 $\mathrm{mg} / \mathrm{kg}$ ) in rat completely restored the memory retention impaired by the inhibitor of COX, thus suggesting that $\mathrm{MB}$ can compensate inhibited mitochondrial respiration in brain (20). Moreover, Callaway et al. (18) reported that MB improves cognitive functions in normal rats by increasing the brain cytochrome c oxidase activity. Recently, Atamna et al. (9) demonstrated that nanomolar range of MB delays cellular senescence of normal human fibroblasts and increases oxygen consumption, heme synthesis and resistance to oxidative damage. Interestingly, $\mathrm{MB}$ could also increase the cellular contents of cytochrome c oxidase.

The objective of this study was to evaluate in vitro the protective effect of MB on LSFC cells in two culture conditions as stable and acidotic media. COX activity in LSFC disease is variable according to the tissues (4). The most important decreases are observed in brain, liver and lungs with only 10 to $20 \%$ of the normal COX activity (4). However, cultures of LSFC cells of brain, liver or lungs are not available to evaluate the potential of drugs such as methylene blue. Moreover, there is no animal model. In a previous work, Merante et al. (4) reported that the COX activity of fibroblasts isolated from LSFC patients, cultivated in normal conditions, was decreased about fifty percent in comparison with normal skin fibroblasts. Given that skin fibroblasts are much easier to obtain, this model was chosen for the present study. As reported in the literature (4), COX activity in both LSFC cells was reduced about fifty percent in comparison with normal skin fibroblasts, WS1. 
A

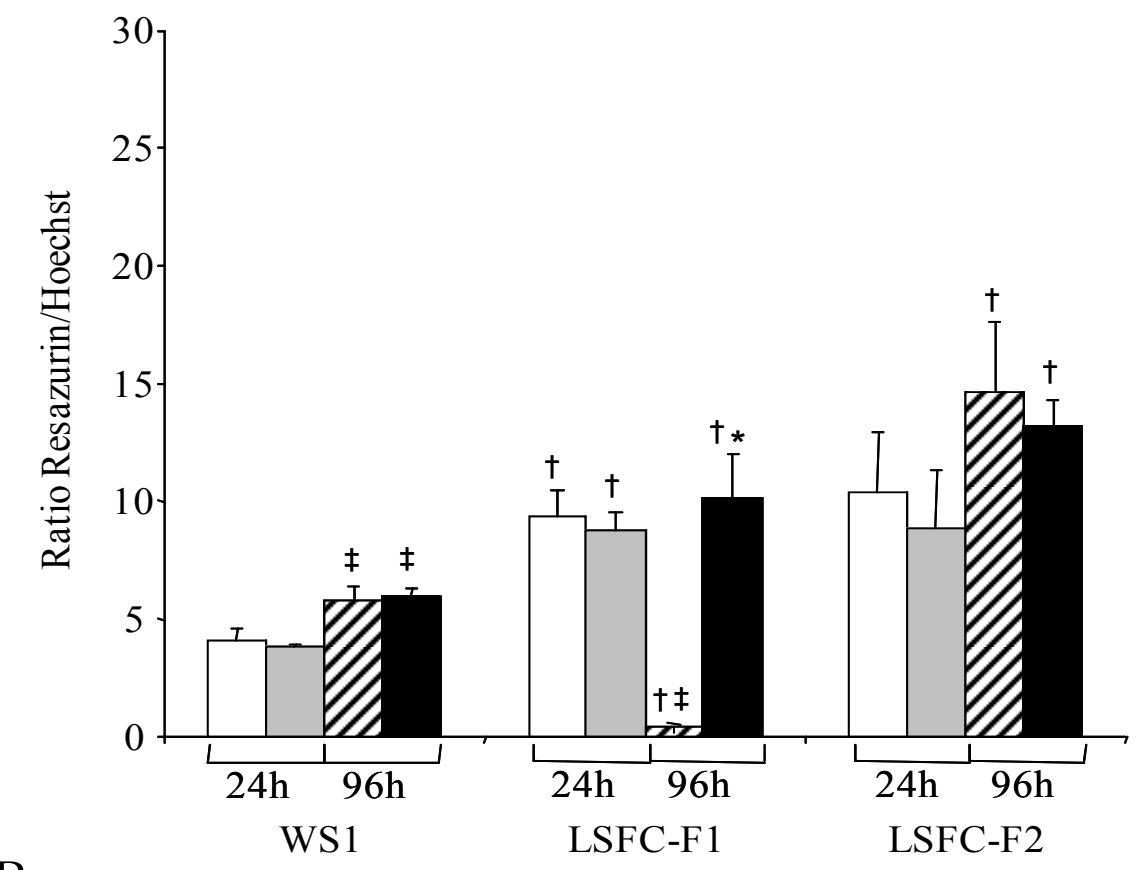

B

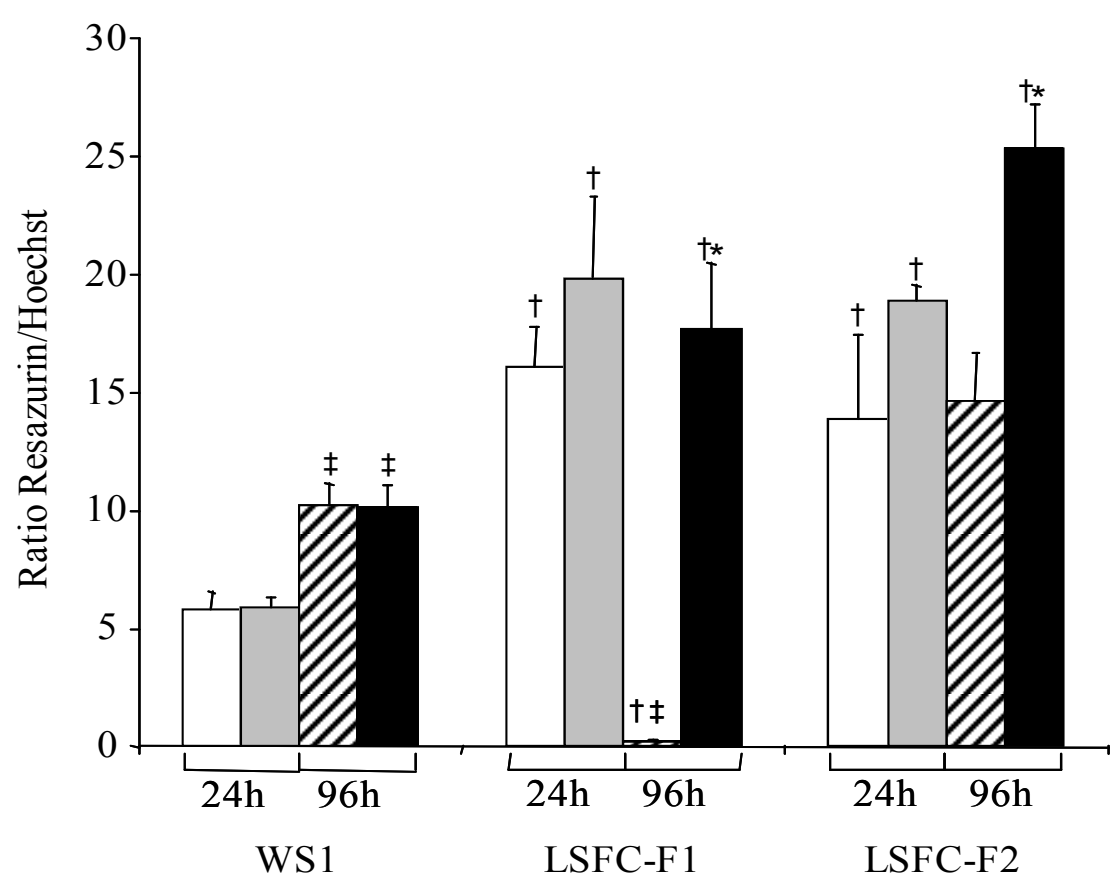

Figure. 3 Effect of methylene blue on the metabolic activity of normal (WS1) and LSFC skin fibroblasts in stable medium (A) and acidotic medium (B). The cells were incubated for $24 \mathrm{~h}$ (white) or $96 \mathrm{~h}$ (dashed) in the absence or in the presence of $125 \mathrm{nM}$ methylene blue (gray \& black). Data represent the means \pm standard deviation of at least six determinations. Statistical analysis was performed independently for each cell type in each medium. LSFC cells were also compared with normal skin fibroblasts according to the time and the treatment. *Significantly different from MB-untreated cells for LSFCF1 or LSFC-F2. "Significantly different from cells at $24 \mathrm{~h}$ for WS1 or LSFC-F1. "Significantly different from normal skin fibroblasts WS1 with regard of time and treatment for LSFC-F1 or LSFC-F2. P $\leq 0.05$, one-way ANOVA analysis and post-hoc Bonferroni test. 
A
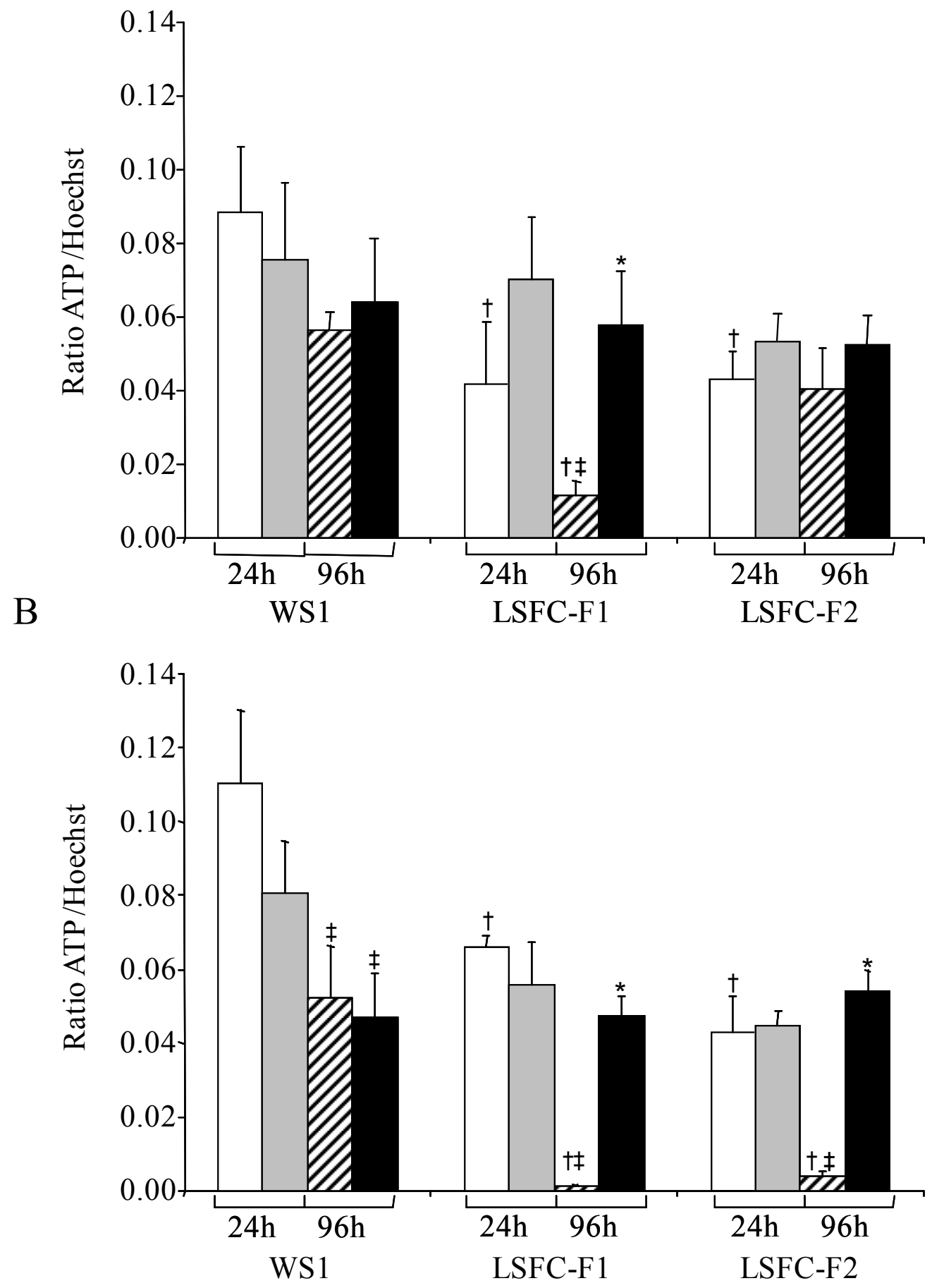

Figure. 4 Effect of methylene blue on the ATP content of normal (WS1) and LSFC skin fibroblasts in stable medium (A) and acidotic medium (B). The cells were incubated for $24 \mathrm{~h}$ or $96 \mathrm{~h}$ in the absence (white-) or in the presence of $125 \mathrm{nM}$ methylene blue (gray \& black). Data represent the means \pm standard deviation of at least six determinations. Statistical analysis was performed independently for each cell type in each medium. LSFC cells were also compared with normal skin fibroblasts according to the time and the treatment. *Significantly different from MB-untreated cells for LSFC-F1 or LSFCF2. "Significantly different from cells at $24 \mathrm{~h}$ for WS1 or LSFC-F1. 'Significantly different from normal skin fibroblasts WS1 with regard to time and treatment for LSFC-F1 or LSFC-F2. P $\leq 0.05$, one-way ANOVA analysis and post-hoc Bonferroni test. 


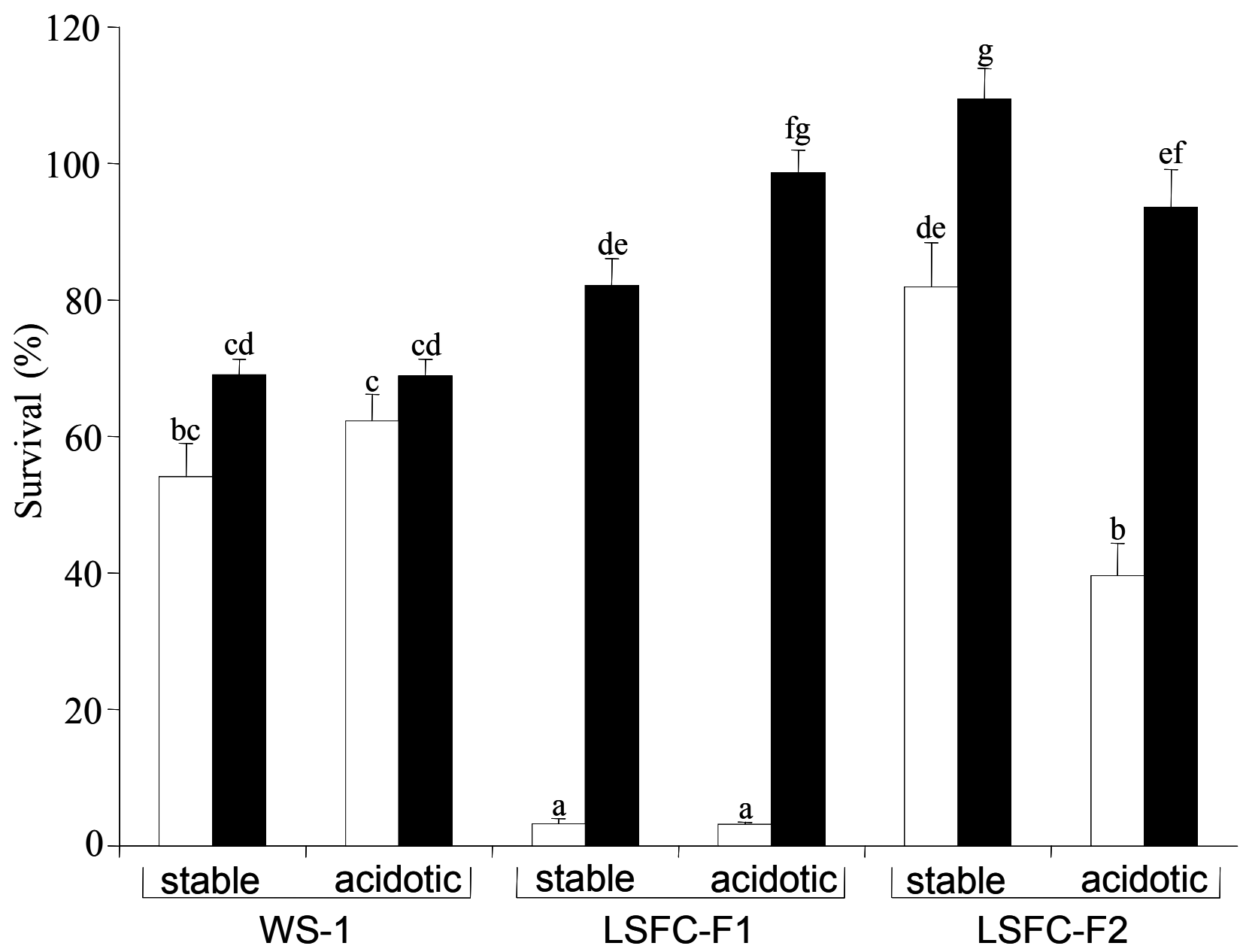

Figure. 5 Effect of methylene blue on the survival of normal and LSFC skin fibroblasts. Each cell line was incubated for 96 hours in stable medium or acidotic medium with (black) or without (white) $125 \mathrm{nM}$ methylene blue. Data represent the means \pm standard deviation of at least six determinations. Means within each group with different letters (a-g) differ significantly from each others. $\mathrm{P} \leq 0.05$, one-way ANOVA analysis and post-hoc Bonferroni test.

Using these cellular models, we tested the effect of MB on metabolic activity, ATP content and survival in two culture conditions as stable and acidotic media.

Metabolic activity was measured using resazurin which is a redox indicator dependent on cellular reduced equivalents such as NADH and NADPH. Non-fluorescent resazurin is irreversibly reduced to fluorescent resorufin by NADHdependent oxido-reductase (21). The reduction of resazurin is shown to be dependent on both glycolytic and oxidative metabolism (22). Therefore, resazurin was used to determine general metabolic activity including mitochondrial function (23-26). Interestingly, our results show that the metabolic activity at 24 hours was found generally higher in both LSFC cell lines in comparison with normal cells. This observation could be due, in part, to the accumulation of reduced equivalents as NADH possibly caused by a decreased COX activity and sustained glycolysis (4). The $\mathrm{NADH} / \mathrm{NAD}+$ ratio is implicated in the regulation of glucose metabolism. Therefore, elevated NADH/NAD+ ratio can cause a blockage of glucose oxidation and reduce the ATP content $(27,28)$. Moreover, the NADH accumulation can lead to the transformation of the pyruvate to lactate through lactate dehydrogenase (29). Intracellular acidification induced by lactic acid could be unfavourable to the preservation of $\mathrm{COX}$ activity 
and this effect may be exacerbated in LSFC cells. After 96 hours in both media, our results indicate that metabolic activity and ATP content were drastically reduced in LSFC-F1. Surprisingly, the compound heterozygous LSFC-F2 was found to be unaffected after 96 hours in the stable medium compared with the acidotic medium and with homozygous LSFC-F1 cells. Moreover, LSFC-F2 was found to be more resistant in the stable medium than normal cells and LSFC-F1 cell lines and more resistant in the acidotic medium compared with LSFC-F1. It is interesting to mention that the compound heterozygous patient survived about twelve acidotic crises. LSFC-F2 resistance could be explained, in part, by a COX VIc polymorphism that replaces an acidic glutamate 62 with a glycine 62 (1). Indeed, this polymorphism possibly decreases the sensitivity of LSFC-F2 cells in acidic conditions avoiding such a decline of the COX activity. This hypothesis may give a physiological clue to the patient's crises. Indeed, that a stress perhaps temporarily lowers the $\mathrm{pH}$ by increasing lactate production and this then lowers the ability of COX to maintain its activity. Testing of this hypothesis is in progress.

Preliminary experiments allowed the determination of the optimal MB concentration at $125 \mathrm{nM}$ (Figure 2). It is important to mention that relatively high concentrations of $\mathrm{MB}(>1 \mu \mathrm{M})$ are cytotoxic for normal and LSFC cell lines (data not shown). These results are in agreement with the literature (9). Our results show that MB prevents decline of metabolic activity as well as maintain redox state and ATP content in both LSFC cells. Moreover, MB improves survival of LSFC cells in both media. It was reported that $\mathrm{MB}+$ can oxidize directly NADH into NAD+ (19) and the MBH2 produced can be re-oxidized directly by molecular oxygen (29-31). Decrease of NADH/NAD+ ratio by MB could prevent intracellular acidification and the inhibition of the glycolysis and possibly oxidative metabolism including COX activity. Moreover, in the cells $\mathrm{MB}+$ could also act as an acceptor of hydrogen in several enzymatic systems $(33,34)$, thus favouring the reactions of $\mathrm{MBH} 2$ with the heme group of proteins $(32,35)$. As proposed by Atamna et al. (9) in IMR90 lung fibroblasts, it is possible that $\mathrm{MB}+$ and $\mathrm{MBH} 2$ could serve as electron carriers between $\mathrm{NAD}(\mathrm{P}) \mathrm{H}$-dependent dehydrogenase of mitochondrial complex I and the heme groups of $\mathrm{COX}$. The $\mathrm{MB}+/ \mathrm{MBH} 2$ redox- cycling in mitochondria of LSFC cells could increase COX activity, consumption of oxygen and maintain ATP content. On the other hand, MB might also increase COX components of mitochondrial complex IV in LSFC cells as shown by Atamna et al. (9) in IMR90 lung fibroblasts. However, complementary studies will be necessary to confirm these hypotheses. Finally, in a previous clinical study, the treatment of five patients with intravenous $\mathrm{MB}$ had a demonstrable effect on all five patients, resulting in a lowering of the lactate/pyruvate ratio, a pronounced decrease of excess lactate, and may have contributed to the survival of one patient (33).

In conclusion, the results presented in this study show that a very low concentration of MB can prevent the decline of metabolic activity in LSFC cells and the decrease of ATP content. Moreover, MB was found to strongly improve the survival of LSFC cell lines suggesting that it could prevent acidotic crises. The fundamental decompensation in acidotic crises of LSFC patients is a frequent cause of fatality and thus any manipulation with drugs that can defray the cytotoxic events in crisis could be enormously advantageous. To the best of our knowledge, MB therapy was never tested on lactic acidosis induced by inherited metabolic disorders such as LSFC. It would be interesting to investigate the protective effect of MB at very a low dose in LSFC disease in vivo.

\section{REFERENCES}

1. Lee N, Daly MJ, Delmonte T, Lander ES, Xu F, Hudson TJ, Mitchell GA, Morin CC, Robinson BH, Rioux JD. A genomewide linkage-disequilibrium scan localizes the Saguenay-Lac-Saint-Jean cytochrome oxidase deficiency to $2 \mathrm{p} 16$. Am J Hum Genet, 2001; 68:397-409.

2. Mootha VK, Lepage $\mathrm{P}$, Miller K, Bunkenborg J, Reich M, Hjerrild M, Delmonte T, Villeneuve A, Sladek R, Xu F, Mitchell GA, Morin C, Mann M, Hudson TJ, Robinson B, Rioux JD, Lander ES. Identification of a gene causing human cytochrome $\mathrm{c}$ oxidase deficiency by integrative genomics. Proc Natl Acad Sci USA, 2003; 100:605-610.

3. Morin C, Mitchell G, Larochelle J, Lambert M, Ogier H, Robinson BH, De Braekeleer M . Clinical, Metabolic, and Genetic Apects of Cytochrome C Oxidase Deficiency in Saguenay-Lac-St-Jean. Am J Hum Genet, 1993; 53:488-496.

4. Merante F, Petrova-Benedict R, MacKay N, Mitchell G, Lambert M, Morin C, De Braekeleer M, 
Laframboise R, Gagne R, Robinson BH. A biochemically distinct form of cytochrome oxidase (COX) deficiency in the Saguenay-Lac-Saint-Jean region of Quebec. Am J Hum Genet, 1993; 53:481487.

5. Sasarman F, Brunel-Guitton C, Antonicka H, Wai T, Shoubridge EA. LRPPRC and SLIRP interact in a ribonucleoprotein complex that regulates posttranscriptional gene expression in mitochondria. Molecular Biology of the Cell, 2010; 21:1315-1323.

6. Lindahl PE, Öberg KE. The effect of rotenone on respiration and its point of attack. Exp Cell Res, 1961; 23:228-237.

7. Visarius TM, Stucki JW, Lauterburg BH. Inhibition and stimulation of long-chain fatty acid oxidation by chloroacetaldehyde and methylene blue in rats. J Pharmacol Exp, 1961; 289:820-824.

8. Riha PD, Bruchey AK, Echevarria DJ, GonzalezLima F. Memory facilitation by methylene blue: Dose-dependent effect on behaviour and brain oxygen consumption. Eur J Pharmacol, 2005; 511:151-158.

9. Atamna H, Nguyen A, Schultz C, Boyle K, Newberry J, Kato H, Ames BN. Methylene blue delays cellular senescence and enhances key mitochondrial biochemical pathways. FASEB J, 2008; 22:703-712.

10. Coelho JC, Giugliani R. Fibroblasts of skin fragments as a tool for the investigation of genetic diseases: technical recommendations. Genet Mol Biol, 1999; 23:269-271.

11. Pitkanen S, Raha S, Robinson BH. Diagnosis of complex I deficiency in patients with lactic acidemia using skin fibroblast cultures. Biochem Mol Med, 1996; 59:134-137.

12. Smith PK, Krohn RI, Hermanson GT, Mallia AK, Gartner FH, Provenzano MD, Fujimoto EK, Goeke NM, Olson BJ, Klenk DC. Measurement of protein using bicinchoninic acid. Anal Biochem, 1985; 150:76-85.

13. Kramer KA, Oglesbee D, Hartman SJ, Huey J, Anderson B, Magera MJ, Matern D, Rinaldo P, Robinson BH, Cameron JM, Hahn SH. Automated Spectrophotometric Analysis of Mitochondrial Respiratory Chain Complex Enzyme Activities in Cultured Skin Fibroblasts. Clin Chem, 2005; 51: 2110-2116.

14. O'Brien J, Wilson I, Orton T, Pognan, F. Investigation of the Alamar Blue (resazurin) fluorescent dye for the assessment of mammalian cell cytotoxicity. Eur J Biochem, 2000; 267:54215426.

15. Larsson R, Nygren P. A rapid fluorometric method for semiautomated determination of cytotoxicity and cellular proliferation of human tumor cell lines in microculture. Anticancer Res, 1989; 9:1111-1119.
16. Yang N, Ho W, Chen Y, Hu M. A convienient onestep extraction of cellular ATP using boiling water for the luciferin-luciferase assay of ATP. Anal Biochem, 2002; 306:323-327.

17. Wang XM, Terasaki PI, Rankin GW Jr, Chia D, Zhong HP, Hardy S. A new microcellular cytotoxicity test based on calcein AM release. Hum Immunol, 1993; 37:264-270.

18. Callaway NL, Riha PD, Bruchey AK, Munshi Z, Gonzalez-Lima F. Methylene blue improves brain oxidative metabolism and memory retention in rats. Pharmacol Biochem Behav, 2004; 77:175-181.

19. Visarius TM, Stucki JW, Lauterburg BH. Stimulation of respiration by methylene blue in rat liver mitochondria. FEBS Lett, 1997; 412:157-160.

20. Callaway NL, Riha PD, Wrubel KM, McCollum D, Gonzalez-Lima F. Methylene blue restores spatial memory retention impaired by an inhibitor of cytochrome oxidase in rats. Neurosci Lett, 2002; 332:83-86.

21. Barnes S, Spenney JG. Stoichiometry of the NADHoxidoreductase reaction for dehydrogenase determinations. Clin Chim Acta, 1980; 107:149-154.

22. Abe T, Takahashi S, Fukuuchi Y. Reduction of Alamar Blue, a novel redox indicator, is dependent on both the glycolytic and oxidative metabolism of glucose in rat cultured neurons. Neurosci Lett, 2002; 326:179-182.

23. Springer JE, Azbill RD, Carlson SLA. Rapid and sensitive assay for measuring mitochondrial metabolic activity in isolated neural tissue. Brain Res Protoc, 1998; 2:259-263.

24. Magnani E, Bettini E. Resazurin detection of energy metabolism changes in serum-starved PC12 cells and of neuroprotective agent effect. Brain Res Protoc, 2000; 5:266-272.

25. Yang Y, Balcarcel RR. 96-well plate assay for sublethal metabolic activity. Assay Drug Dev Technol, 2004; 2:353-361.

26. Zhang HX, Du GH, Zhang JT. Assay of mitochondrial functions by resazurin in vitro. Acta Pharmacol Sin, 2004; 25:385-389.

27. Tilton WM, Seaman C, Carriero D, Piomelli S. Regulation of glycolysis in the erythrocyte: role of the lactate/pyruvate and NAD/NADH ratios. J Lab Clin Med, 1991; 118:146-152.

28. Holness MJ, Sugden MC. Regulation of pyruvate dehydrogenase complex activity by reversible phosphorylation. Biochem Soc Trans, 2003; 31:1143-1151.

29. Robinson BH, Taylor J, François B, Beaudet AL, Peterson DF. Lactic acidosis, neurological deterioration and compromised cellular pyruvate oxidation due to a defect in the reoxidation of cytoplasmically generated NADH. Eur J Pediatr, 1983; 140:98-101. 
30. May JM, Qu Z, Cobb CE. Reduction and uptake of methylene blue by human erythrocytes. Am J Physiol-Cell Physiol, 2004; 286:C1390-C1398.

31. Harrop GA Jr, Barron G. Studies on blood cell metabolism. I. The effect of methylene blue and other dyes upon the oxygen consumption of mammalian and avian erythrocytes. J Exp Med, 1928; 48:207-223.

32. McCord JM, Fridovich I. The utility of superoxide dismutase in studying free radical reactions. II. The mechanism of the mediation of cytochrome $\mathrm{c}$ reduction by a variety of electron carriers. J Biol Chem, 1970; 245:1374-1377.

33. Tranquada RE, Bernstein S, Grant WJ. Intravenous Methylene Blue in The Therapy of Lactic Acidosis. Arch Intern Med, 1964; 114:13-25.

34. Quastel JH. Use of Artificial Electron Acceptors in Study of Dehydrogenase. Method Enzymol, 1957; 4:330-331.

35. Metz EN, Balcerzak SP, Sagone AL Jr. Mechanisms of methylene blue stimulation of the hexose monophosphate shunt in erythrocytes. J Clin Invest, 1976; 58:797-802. 